\title{
DANÇA DE RUA: JOVENS ENTRE PROJETOS DE LAZER E TRABALHO
}

\author{
MÁRCiA MATHIAS NETTO FLEURY*
}

\begin{abstract}
RESUMO
Pretendeu-se neste trabalho compreender os processos de construção de identidades juvenis urbanas partindo das expressões culturais do grupo Dançarinos de Rua que se identifica com a cultura hiphop. Os integrantes deste grupo tinham de 15 a 24 anos de idade em 2004, quando iniciada a pesquisa de campo. Foi realizada pesquisa que assumiu características etnográficas, com observação e escuta de relatos dos jovens do grupo, em espaços públicos, como o Campo de São Bento, em Niterói, onde o grupo Dançarinos de Rua realizava atividades que podem ser definidas como práticas culturais que combinavam simultaneamente com propostas de lazer, busca de prestígio social e possibilidade de inserção no mundo do trabalho artístico-cultural. Observou-se que a sociabilidade do grupo permitiu provisoriamente, a construção de um projeto coletivo em torno da dança, tendo como questão de fundo o associativismo, ou seja, o caminhar juntos, procurando transformar o lazer em trabalho remunerado, e garantindo a sobrevivência.
\end{abstract}

Palavras chave: Cultura, Juventude, Trabalho, Associativismo

* Mestra em Educação na área de Desigualdades Sociais, Identidade e Educação. Correo electrónico: marciafleury@gmail.com. 


\section{RESUMEN}

\section{BAILE DE CALLE: JÓVENES ENTRE PROYECTOS DE RECREACIÓN Y TRABAJO}

En este trabajo se pretendió comprender los procesos de construcción de identidades juveniles urbanas, partiendo de las expresiones culturales del grupo Dançarinos de Rua que se identifican con la cultura hiphop. Los integrantes del grupo tenían entre 15 y 24 años de edad en el año 2004 cuando se inició el trabajo de campo. La investigación asumió características etnográgicas, con observación y escucha de relatos de los jóvenes del grupo en espacios públicos, como el Campo de São Bento, en Niterói, donde el grupo Dançarinos de Rua realizaba actividades que pueden ser definidas como prácticas culturales que combinaban simultáneamente con propuestas de recreación, búsqueda de prestigio social y posibilidades de inserción en el mundo del trabajo artísticocultural. Se observó que la sociabilidad del grupo permitió provisoriamente la construcción de un proyecto colectivo en torno al baile, teniendo como cuestión de fondo el asociativismo, o sea, el caminar juntos, procurando transformar la recreación en trabajo remunerado, garantizando la sobrevivencia.

Palabras clave: Cultura, Juventud, Trabajo, Asociativismo

\section{AbSTRACT \\ STREET DANCE: YOUNG PEOPLE BETWEEN RECREATION PROJECTS AND WORK}

It was intended in this research to understand the processes of construction of the urban juvenile identities starting from the cultural expressions of the group Street Dancers who identify themselves with the hiphop culture. The integrants of this group were between 15 and 24 years old in 2004, when the field research was initiated. A research that assumed ethnographic characteristics was made, with observation and listening of statements of the youth of the group, in public spaces, as the Campo de São Bento, in Niterói, where the group Street Dancers did activities that can be defined as cultural practices that combined simultaneously with leisure proposals, search for social recognition and possibility of insertion in the artistical-cultural working world. It was observed that the group sociability enabled provisionally, the construction of a collective project around the dance, having as main question associationism, that is, walking together searching to transform leisure in paid work and garanty of survival.

KEY WORDS: CUlTURE, YOUTH, WORK, ASSOCIATIONISM 
CONHECEMOS O GRUPO DE dança de rua, caminhando pelo Campo de São Bento, no ano de 2004. O grupo denomina-se Dançarinos de Rua que nesta época era composto por nove jovens que estudam ou trabalham durante o dia e à noite dançam. Eles dançam break e se identificam com o movimento hiphop. A partir desse encontro casual, iniciamos o trabalho de investigação de campo para a dissertação de mestrado da Universidade Federal Fluminense. O problema central da pesquisa foi investigar as identidades culturais do grupo Dançarinos de Rua, observadas em suas práticas de lazer. É da parte destes jovens que se dedica este trabalho.

Algumas áreas da cidade de Niterói parecem favorecer as práticas culturais, como o Campo de São Bento, utilizado pelo grupo Dançarinos de Rua para os ensaios de dança. Eles residem em bairros distantes e precisam utilizar o ônibus para chegarem até o local. O Campo de São Bento fica situado na zona sul da cidade, no bairro de Icaraí. Principalmente nos fins de semana há grande movimentação de pessoas para este bairro, são indivíduos que buscam o lazer e o esporte. No campo há atividades como: ginástica, dança, capoeira, feira de artesanato e apresentação de músicos.

A partir das narrativas dos jovens, buscamos a compreensão dos processos sociais que formam suas identidades, procurando analisar «as redes de aprendizagem e sociabilidade» que eles apresentam.

Observamos as relações que estes jovens estabelecem, como constroem suas experiências de lazer nos espaços públicos da cidade e constatamos o caráter educativo e cultural de suas práticas de «ludicidade», assim como, seus processos de identificação e construção de identidades.

Com a pretensão de compreender a construção de cada jovem como sujeito, buscamos entender seus estilos de vida, suas relações no grupo de dança de rua, nos espaços de lazer que freqüentam. Durante um ano e seis meses acompanhamos o grupo.

Procuramos conceituar os fenômenos culturais da juventude, nesse percurso encontramos autores como Cárdia (1997), Islas (1999), Abramo (2000), Herschmann (2000), Sposito ( 2001), Velho (2003), Carrano (2002) e Dayrell (2005) que demonstram, em suas pesquisas, como se dá a construção das culturas juvenis na sociedade; estes autores dão especial destaque ao tema da diversidade.

Apresentamos as práticas sociais e culturais do grupo, na cidade, a identificação com o movimento hiphop e a construção dos processos e projetos dos seus componentes, evidenciando a possibilidade de 
inclusão social juvenil através dos grupos de dança. Esses jovens têm uma vida simples e precisam trabalhar para ajudar suas famílias. Analisando os dados levantados, procuramos compreender o cotidiano de cada um e encontramos aspectos como: a solidariedade, o lazer, conflitos e a busca de emprego, onde observamos a dinâmica do grupo e a trajetória de cada um de seus componentes.

Investigamos o que representa para cada um dos jovens da pesquisa fazer parte de um grupo de dança. Procuramos enxergar seus interesses, reações e necessidades exigidas pela vida social que subvertem a prática e provocam rupturas e reconstruções dos objetivos traçados, assim como percebemos, através de seus relatos, o «jogo de cintura» que representam com seus corpos na dança e com as atitudes do cotidiano.

Acreditamos como Dayrell (2005:17) na importância de pesquisas na área de educação que permitem inventariar saberes e culturas. Focalizar as culturas juvenis permite ao educador envolver-se com um processo educativo que pode possibilitar a legitimação dos anseios desses jovens e a observar como se processa a construção das identidades juvenis, partindo de relatos dos próprios sujeitos.

Assim, procuramos neste trabalho mostrar as experiências desses jovens com a arte, compreendendo que lançar nosso olhar de educadores à juventude e suas manifestações fora do contexto escolar permitem que observemos como esses estão vivendo a busca de identidade no momento anterior à vida adulta. E, esta questão tornou-se importante ao longo do trabalho por apontar-nos os modos de viver e vencer as dificuldades da vida cotidiana, narradas pelos próprios sujeitos.

\section{A COMPREENSÃO DOS FENÔMENOS CULTURAIS JUVENIS}

A juventude constitui um momento determinado, mas não se reduz a uma passagem. É um processo influenciado pelo meio social do qual o jovem faz parte e pelas trocas que faz com este meio. A observação de grupos revela-nos «juventudes», e esta noção enfatiza a diversidade de «modos de ser jovem» existentes. Atualmente, o funk e o hiphop, com a música, a dança, o desenho e os trajes: calças largas, bonés, correntes no pescoço são as manifestações que podemos observar em determinadas culturas juvenis. Esta arte invadiu as ruas (Melucci, 1992; Carrano, 2002; Dayrell, 2005).

A juventude se evidencia quando o indivíduo esboça necessidade de independência em relação à família e começa a buscar a auto- 
suficiência. O desenvolvimento se dá de forma contínua e o jovem inicia na adolescência seus contatos com grupos de acordo com seus interesses e possibilidades de escolhas, ampliando assim, sua experiência de vida.

Estudos recentes sobre os jovens urbanos e suas diversas formas simbólicas e identidades estão em torno da identidade cultural e as identidades sociais.

Uma opção para entendermos os processos culturais da juventude é buscarmos nas narrativas destes jovens, o sentido que cada um dá as suas experiências artísticas. As produções culturais expressam o modo de ser e sentir de cada um. No entanto, devemos evitar dar ênfase demasiada ao particular deixando de ver o todo. As produções culturais são fenômenos de expressão da identidade do homem: o seu ser e o seu fazer, a identidade e produções culturais requerem uma compreensão unitária e às vezes analógica. Isto é, a identidade não é previamente determinada, tendo plasticidade como a existência humana.

Sendo assim, cultura e identidade não podem ser apreendidas de forma estática, demandam uma compreensão dinâmica, de tal forma que podemos vê-las como elementos vivos, nunca como um arquivo.

Entender aspectos da cultura exige imersão no contexto da vida. O que cada um é e como se dão as relações de cada um com os demais. Como conseqüência dessas constatações, a análise cultural não pode partir de categorias universais. O ponto de partida é a vivência e o reconhecimento das produções culturais, não depende de modelos. Tais produções culturais são manifestações vitais que se movem com indeterminação e liberdade.

Hoje, no Brasil, a comunicação visual, principalmente na música juvenil, mostra uma diversidade de estilos e a dimensão dessa comunicação é tão ampla que os conflitos e as diferenças não conseguem ficar ocultos. Essa diversidade e as negociações estabelecidas com a realidade evidenciam a plasticidade dos códigos culturais, não deixando espaço para a territorialidade. Ao mesmo tempo propõe uma relativização da posição da mídia no que diz respeito ao consumo, característica das grandes cidades. Surgem neste contexto, grupos que compartilham interesses e sendo assim, interagem através de uma rede de significados, atuando na esfera coletiva, dentro do mesmo sistema de valores, e na esfera individual.

Segundo (Velho, 2003:21), nessas interações reside um «campo de possibilidades» alimentado pelo meio social e pelas oportunidades e interesses de cada um. Vive-se na sociedade contemporânea uma 
nova dinâmica social: a desterritorialização com a presença virtual que cria novos vínculos e relativiza a simbolização territorial. Percebe-se no processo de globalização uma desconstrução da cultura ocidental, propiciando trocas de hábitos. Nesta descentralização de hábitos e épocas quebram-se os limites territoriais da cultura, gerando a princípio, uma confusão. Esta fusão cultural origina a multiplicidade de significados consumidos, produzidos e reproduzidos, com inúmeras representações coletivas, busca de identidade e desatualização do sentido de tradição. Entretanto, a identidade não é excludente entre tradição e modernidade, pelo contrário, Giménez (1999) afirma que a interação cultural contribui para a revitalização das identidades étnicas e regionais.

$\mathrm{Na}$ rua, nos bares, nos parques ou nos shoppings, esses grupos de jovens formam verdadeiras redes sociais e culturais. É um tempo de exercitarem a «ludicidade e a corporicidade», estas entendidas como as relações lúdicas e corpóreas que os jovens estabelecem com o espaço urbano (Carrano, 2002). São encontros de lazer, prazer e aprender, onde são criados e identificados «códigos e sinais» que fortalecem a comunicação entre eles. Ao mesmo tempo, esses encontros simbolizam a apropriação dos espaços como forma de participação na sociedade.

Entender a juventude como um fenômeno social e cultural implica em dar atenção aos jogos dos sentidos, quase sempre indeterminados e elaborados em dinâmicas lúdicas, nas quais os jovens, não se detém em intelectualizar a tradição ou as identidades culturais.

A cultura juvenil, no sentido amplo refere-se ao conjunto de formas de vida e valores, expressos por coletivas generalizações em resposta às condições da existência social e material.

\section{AS IDENTIDADES URBANAS}

A década de 80 está marcada pela crise econômica, política e social a nível nacional, com efeitos em todos os setores da vida. Os elementos relevantes da crise relacionados com o tema juvenil, que nos chama atenção são: a repercussão da crise nos níveis de vida nos setores médios e populares, aumento dos homicídios na população jovem, diminuição das expectativas de ascensão social, crescente pressão por maior incorporação dos membros da família no mercado de trabalho e o desemprego, afetando fundamentalmente a população jovem.

Esta situação leva os indivíduos a prolongarem sua juventude por não poderem ascender às esferas de trabalho. Um outro fator de 
influência é a exclusão dos jovens das classes menos favorecidas dos espaços institucionalizados, como produto da crise. No final dos anos 80 e início dos anos 90, os jovens descobriram que poderiam criar seus próprios espaços para se manifestarem, cresce o número de bandas e, a seguir outros setores juvenis manifestaram novas simbologias, originando o que podemos chamar de explosão simbólica da diversidade juvenil, nas ruas, nos parques, nas discotecas, revistas, shoppings, bailes, bares com jogos e internet e outros locais onde constroem suas identidades sociais. Nesta época se originam as agregações juvenis.

Para refletir acerca destes agrupamentos juvenis e do surgimento da apropriação dos espaços públicos por jovens que se identificam com a cultura hiphop, traçamos um breve histórico do trajeto dessa cultura da África até o Brasil, desde os anos 20, priorizando o rap.

Com o tráfico de escravos, o negro espalhou-se pelo mundo e, com ele, sua cultura e sua música. Da mesma forma, o negro se apropriou da música religiosa branca européia, transformou-a em música negra e assim no decorrer das décadas e gerações originou outras formas de expressão. Geralmente esta cultura era transmitida pela oralidade, com a característica de falar de seus sentimentos, dos sofrimentos e das dificuldades encontradas em relação ao trabalho, ao presídio, etc. Tal como é hoje a característica do rap.

A cultura das grandes metrópoles vem sendo «africanizada» em vários setores da sociedade mundial, não só na música como nos esportes, na dança, nos anúncios publicitários.

Na Jamaica o blues é revisitado e sua fusão com a música jamaicana origina outros gêneros musicais como: o Ska, ${ }^{1}$ o reggae e o rap. $\mathrm{O}$ reggae chegou a Inglaterra e foi adotado pelos skinheads, grupos que se manifestam com críticas à sociedade. De natureza fascista, esses jovens se encontram em discotecas, se apresentam como uma variante dos rude boys ingleses (gangues inglesas). Os rudies eram grupos de negros, vindos da Jamaica, nos anos 20, e os mods, (de brancos), andavam pelas ruas, freqüentavam bares e ouviam soul americano e ska jamaicano.

Por volta de 1907, os concertos sociais, políticos e espirituais passaram a fazer parte das músicas com a intenção de luta pela descolonização africana, como no caso da música de Bob Marley, que incita guerrilheiros ao campo de batalha na revolução da Rodésia e até hoje

1 Ska, espécie de reggae com ritmo lento. 
é traço de identidade na Jamaica. Parece que a partir daí, o reggae dá gênese ao rap. A partir dos anos 60, na Jamaica nascem os primeiros ensaios do rap.

Em 1970, nos EE.UU. o movimento reggae jamaicano começou a aparecer através de animadores de festas com recriações de ritmos em toca-discos. Podiam ser vistos também nos guetos de Nova York.

A chegada da cultura hiphop e do funk, no Brasil, segundo autores como Vianna (1997); Herschmann (2000), se deu por volta dos anos 80, na cidade de São Paulo, depois no Rio de Janeiro, estendendo-se por todos os centros urbanos do país.

Essas culturas tornaram-se através da identificação, fontes de múltiplas identidades juvenis. Especificamente, tratamos dos grupos que se identificam com o hiphop e se expressam com a dança de rua. Estas manifestações coletivas giram em torno de um fim comum, para o qual se organizam e procuram formas de sobrevivência junto ao sistema e como forma de lazer.

Essas agregações juvenis, principalmente as bandas e os grupos de dança, são compostas por jovens de classes populares e de outras classes, a princípio influenciados pelos meios de comunicação de massa.

As práticas culturais simbólicas juvenis apontam o papel da comunicação na produção, reprodução, inovação e defesa de um discurso próprio, desses jovens frente à sociedade. Esta autora mostra que nos centros urbanos não só aparecem problemas de despersonificação, de oportunidades no sistema produtivo, de satisfação de necessidades, também se produzem redes de convivência e inúmeras práticas simbólicas de atores sociais, de demarcação simbólica de territórios. Fato simbólico que remete ao processo de constituição de múltiplas identidades sociais. Diante desse contexto, qual o papel dessas associações juvenis na sociedade atual?

As identidades se constroem nas interações cotidianas entre sujeitos urbanos e se exteriorizam em formas e contornos. Falar de identidades é falar de classes sociais, de grupos, de trabalho, de práticas cotidianas, de espaços e territórios. As bandas e os grupos de dança são parte do complexo panorama da cultura urbana onde se constroem e reconstroem novas solidariedades e identidades sociais.

Ao observar os agrupamentos juvenis de dança, percebemos a relação que esses atores sociais fazem entre o uso da comunicação e a identidade do grupo, assim como as produções, circulação e reconhecimento de alguns de seus produtos culturais como: propagandas, 
roteiros, páginas na internet, onde se manifesta uma referência situacional ou espacial do grupo, com característica de atuação em determinado local e determinado território que constroem cotidianamente, através de interações e da criação de pontos de encontro para as apresentações. Todas essas estratégias têm como finalidade garantir a continuidade e a reprodução do grupo.

O grupo de dança é um agrupamento solidário que tem uma função integradora, uma forma de socialização alternativa a outras instituições de socialização.

Vemos, em todo o mundo, inúmeras formas de manifestações juvenis, congregação de identidades e de sociabilidade.

Coexistem diversas expressões culturais antagônicas à cultura chamada dominante e esta diversidade cultural torna-se fonte principal de conflitos que marcam as sociedades urbanas contemporâneas. Neste contexto surge a necessidade de os jovens se organizarem em bairros, de utilizarem uma linguagem que os identifique. Adotam signos e símbolos que compartilham como os grafittis nos muros, as tatuagens, o estilo, as relações com o status e o poder, que se tornam evidentes nas reações de valentia entre os jovens.

Estudar as culturas juvenis urbanas (como os grupos de dança), demanda em analisar as subjetividades destes atores sociais e a partir delas tentar compreender os processos através dos quais se constroem as identidades urbanas.

Como produto «natural» de um ambiente adverso, as bandas e os grupos de dança, invadem os espaços urbanos populares, estabelecendo uma nova relação entre o público e o privado. Com a dança de rua nos anos 80, por exemplo, emerge um novo modo de utilização do espaço público.

\section{TRABALHO E PROJETOS}

Os jovens se integram em grupos de dança e vivem experiências de solidariedade, neste espaço-tempo constroem suas identidades, procuram reconhecimento da arte juvenil no sistema educativo e produtivo. Existe um tipo de cenário social e cultural que corresponde a espaços que são apropriados e construídos pelos jovens para produzir cultura, são espaços cuja existência obedece às necessidades de criação artística, de manifestação dos fenômenos que experimentam.

Velho (2003) examina a temática, indivíduo e sociedade, na atual sociedade complexa e aponta como características dessas suas ambi- 
güidades e contradições. Sua investigação a respeito da identidade juvenil, da vida urbana, das possibilidades de trabalho existentes nos dias atuais, remete-nos às relações estabelecidas entre a antropologia $\mathrm{e}$ a história. Sua referência é a sociedade brasileira com seus desafios e contradições.

Nas sociedades complexas coexistem diferentes estilos de vida e visões de mundo, grupos se formam compartilhando crenças e valores, configurando-se como expressão cultural inclusive com uma linguagem que os identifica. É o que constatamos ao observar um grupo de dança de rua, esses aspectos estão presentes nas técnicas do corpo, na apresentação, na linguagem, nos trajes e nos gestos. Interagem através de uma rede de significados e atuam com grande diversidade, estas redes representam campos de possibilidades na sociedade complexa moderna.

A questão que surge é como esses indivíduos desenvolvem suas identidades no contexto globalizado, tão farto de possibilidades quanto de difícil realização de projetos? Os cientistas sociais acreditam que essas redes de relações atravessam o mundo da família, do bairro, dos grupos de status, etnias e classes sociais. Vêem-se nesses grupos combinações e identidades particulares individualizados. O trabalho e a política em transformações são fatores que estimulam essas travessias sociológicas.

O que percebemos nas sociedades complexas, principalmente nas grandes metrópoles, é uma diversidade de papéis e identidades que revelam uma multiplicidade de estilos de vida. Segundo Velho (2003:26), «os indivíduos transitam entre os domínios do trabalho, do lazer, do sagrado, etc., com passagens às vezes quase imperceptíveis»». Estes indivíduos vivem múltiplos papéis, de acordo com seu movimento na sociedade.

Nesse contexto, a coexistência de diferentes mundos vividos pelos seus atores constitui a sua própria dinâmica. É interessante ressaltar que os jovens, enquanto se deslocam nas diferentes esferas que atuam, partilham de códigos diferentes em suas trajetórias. Uma contradição fica evidente, ou seja, o individualismo da vida moderna, metropolitana, não exclui as experiências comunitárias e atingem dimensões simbólicas.

Os atores sociais estão em constante adaptação de valores e ideologias individualistas, constitutivas da vida moderna. Os processos globalizados expandem e generalizam esta situação e nesse contexto, torna-se um desafio para a sociedade contemporânea entender o processo cultural juvenil, principalmente nas grandes cidades. $\mathrm{O}$ processo 
mais evidente na sociedade contemporânea é a massificação. A urbanização, o desenvolvimento das grandes cidades, os meios de comunicação, os avanços tecnológicos produziram transformações na história da humanidade e alterações nos padrões de sociabilidade, e, interações nos hábitos e rotinas. Entretanto, cada região lida com as mudanças de forma distinta (Velho, 2003:26).

Um dos exemplos são o rap e a dança de rua que assistimos nos meios de comunicação, as manifestações de bandas, grupos de dança de várias partes do mundo. Existem semelhanças, mas as diferenças são significativas, até mesmo porque a linguagem do rap aponta e denuncia o contexto social dos seus autores. Este já é um ponto que promove diferentes representações e simbologias.

Há uma produção cultural na mídia que valoriza determinados dados sociais e há o rap da periferia que não é absorvida integralmente pelos padrões estabelecidos pelas indústrias culturais. Este é outro ponto de divergência e diferenciação na questão. Além disso, há o aspecto individual de interpretação dessas linguagens. Logo, existe um dinamismo de múltiplos significados. No plano da constituição da subjetividade e das culturas juvenis a questão da participação política dá-se através da música de protesto ou denúncia. Ainda no plano individual esta participação evidencia a característica de multiplicidade de papéis. O indivíduo participa de um grupo de rap, trabalha no comércio e estuda. São aspectos diferentes, complementares, que estão em continuo movimento, na experiência social e na personalidade de cada um.

Nas sociedades complexas, os atores sociais são estimulados e pressionados assumindo determinados papéis e identidades, mas isso ocorre num quadro de alternativas e opções. Há um permanente processo interativo onde os indivíduos se movem de um grupo a outro. Nessas interações, as possibilidades apresentadas geram identidades multifacetadas.

Pais (2004:66) alerta para a existência de caminhos labirínticos praticados pelos jovens num mundo de incertezas que os condena ao trabalho flexível ou precário. Em conseqüência da precariedade de oferta de trabalho fixo, da competitividade e do desemprego, o modelo de sucesso estabelecido pelos sistemas educacionais é colocado em xeque. Em lugar do trabalho fixo os jovens encontram trabalhos provisórios, informais como estratégias de sobrevivência. Assim, a vida social se organiza num processo que acompanha um crescimento dos mecanismos de desestruturação institucional. Neste contexto adverso como os jovens reagem? 
Muitos jovens situam-se em «zonas-sombra» da sociedade, onde podem exercer alguma atividade lucrativa sem pagar impostos. Outros, na luta pela sobrevivência inventam formas de ganhar dinheiro não associadas as «identidades negativas». $\mathrm{O}$ trabalho precário pode ser educativo ao permitir que o jovem reflita sua condição, levando-o a ultrapassar desafios.

Quanto à reação dos jovens a aleatoriedade da vida, a postura é diversificada, uns aceitam com realismo procurando enfrentar as dificuldades, outros, reagem com pessimismo cínico, com aparente indiferença.

Alguns jovens inclinam-se a negar a realidade através de «projeções utópicas» e alguns se sentem perdidos em relação às escolhas que precisam fazer e às decisões em relação ao trabalho. Dentro do que idealizam como saída encontram obstáculos e muitos se desencantam. Este processo estabelece o jogo da vida, ora de encontros, ora de desencontros, seguindo de um lugar para o outro, refazendo sonhos e projetos.

Assistimos a esses momentos oscilatórios que fazem parte do cotidiano de todos, principalmente dos indivíduos mais jovens. Diversos são os fatores que contribuem para estes momentos oscilatórios, os jovens desenvolvem uma espécie de tributo à extravagância e à boêmia, procurando chocar a sociedade e ao mesmo tempo fazer suas experimentações para desenvolverem sociabilidades entre seus pares. Outro aspecto que pode ser observado entre os jovens é uma tendência a relativização das coisas como diplomas e empregos.

É importante ressaltar a importância do retardamento da entrada dos jovens na vida adulta, que ocorre devido ao prolongamento das trajetórias escolares e as dificuldades de seu ingresso no mercado de trabalho de forma estável.

Segundo Porsmann (2006), no Brasil em 1989, havia 1 milhão de jovens desempregados, em 1998 esse número subiu para 3,3 milhões ou seja, $194,8 \%$ a mais. Na educação, apesar do acréscimo de procura nas universidades, de 30,1 milhões de jovens brasileiros apenas $10 \%$ têm acesso à universidade.

As gerações mais velhas procuram orientar os jovens para o cotidiano da rotina e para a busca de segurança, os jovens escolhem, muitas vezes, os caminhos e os valores da ruptura. Trata-se de um tempo de experimentações e um momento favorável à formação de agregações juvenis. 
Diante de todas as incertezas e instabilidades do tempo contemporâneo, alguns jovens buscam no tempo ocioso fugir dessa realidade, compensando em aventuras e sonhos nem sempre realizáveis. O cotidiano juvenil às vezes se apresenta como um tempo de deriva com imprevisíveis rotas incertas. Essas rotas não são necessariamente passivas e com rotinas. As rotinas são quebradas por outras experiências vividas e dessas rupturas emergem os valores desses jovens. Dessa forma a vida é vivida com riscos, investimentos, criatividade e desvios que levam o jovem à conquista de sua identidade.

$\mathrm{Na}$ medida que o indivíduo se destaca e é cada vez mais sujeito, muda o caráter de sua relação com as instituições. Novas formas de sociabilidade serão elaboradas, acompanhando os paradigmas emergentes.

No plano da realização de projetos voltados para as expressões artísticas juvenis, na área da dança de rua vemos que há uma dificuldade em realizá-los, profissionalmente. As expressões juvenis através da arte, do corpo, salientam as ações vividas pela sociedade em dado momento. Eles retratam nos rituais, nos trajes, no próprio corpo e na linguagem, à sociedade da qual fazem parte com suas contradições, ambivalências, sonhos e dificuldades.

\section{GRUPO DE DANÇA: ESPAÇO INFORMAL DE APRENDIZAGEM}

Nos últimos dez anos a forma agregativa pela qual os jovens vêm se organizando chama atenção à investigação. Eles se agrupam na dança, em bandas e cada um aponta importantes dados para o conhecimento das relações na sociedade, assim como, para a construção de identidades. Os grupos de dança trazem aspectos importantes à investigação pela diversidade de identidades juvenis e práticas culturais, verificadas nas relações que eles estabelecem com seus pares, pelo sentido que dão ao consumo para a produção cultural e pela apropriação do espaço público no processo de construção da sociabilidade.

A dança nos grupos juvenis possibilita experiências educativas que parecem dar sentido às suas vidas naquele momento. Os jovens, nesse sentido, são agentes de produção de cultura e conhecimento, procuram enfrentar situações do cotidiano e transformar o momento vivido superando a falta de trabalho. Neste caso, apelam para a criatividade, para saberes que delineiam suas realidades, usados para a superação de dificuldades encontradas em relação às escassas oportunidades de trabalho. 
A questão mais importante deste trabalho é trazer pistas para a compreensão da cultura do grupo Dançarinos de Rua e sua identificação com o hiphop. A linguagem do hiphop é multifacetada: gestos corporais, ritmo, desenhos (grafite), poesia. Nossa investigação está centrada na dança, por ser esta o interesse dos sujeitos desta pesquisa. Há uma particularidade a ser ressaltada, a linguagem e a arte no hiphop estão abraçadas, promovendo a comunicação e ressignificação de elementos dessa comunicação.

A experiência dos grupos musicais mostra que o rap constitui uma oportunidade de esses jovens vivenciarem a etapa da juventude em busca de identidades e nos grupos, procuram transformar suas idéias, gestos e desejos, saindo da infância e partindo para a construção de novos referencias, fora do grupo familiar. Dayrell (2005:112), acentua que os grupos se constituem como «momento próprio de experimentações, de descoberta e teste das próprias potencialidades, de demandas de autonomia que efetivam no exercício de escolhas. A turma de amigos cumpriu um papel fundamental».

As manifestações culturais como o hiphop têm contribuído para evidenciar o processo sociocultural contemporâneo, essas expressões culturais juvenis vêm chamando a atenção nas pesquisas, para o consumo e a globalização (Vianna,1997; Herschmann, 2000). Os trabalhos realizados na área das expressões culturais revelam o tempo atual, as características do contexto globalizado e os aspectos da lógica interna das ações dos agentes sociais envolvidos.

O hiphop emergiu nos anos setenta, nos EUA, como forte referencial que permitiu a configuração de identidades juvenis partindo de linguagens que vinham das ruas, dos guetos e de grupos de bairro. Nos EUA, muitos artistas dançarinos e fãs do hiphop continuam a pertencer a um sistema elaborado de grupos onde as identidades são mostradas a partir das músicas, das vestimentas, na dança e estão ligadas à experiência local e ao status conquistado por cada grupo em sua localidade. Esses grupos contribuem para a construção de redes de comunicação que ultrapassam os limites regionais. O hiphop no Brasil, surgiu em meados da década de 80, nos salões da noite paulistana, no circuito negro e popular. Logo se organizou em associações ou «posses», aparecem pequenas gravadoras e assim aconteceu a apropriação dessa cultura pelos consumidores paulistas e cariocas. Como ocorreu em outros países, os jovens brasileiros ressignificaram o hiphop. Um dos precursores foi o rapper Nelson, na Praça da Sé, em São Paulo. Logo após surge o 
programa de rádio dirigido por Dr. Rap, na rádio metropolitana FM. Todas as representações do hiphop têm importância no estudo da dinâmica das culturas contemporâneas por apresentar em diversidade em seus processos de comunicação, em seus rituais, nas relações com os pares, nas práticas sociais dos sujeitos envolvidos com essas expressões, até mesmo por imitação, apresentam riqueza de dados para a investigação das ações desses jovens, nos espaços de sociabilidade, onde fazem emergir dispositivos de produção cultural da sociedade, ressignificando e organizando as tendências veiculadas pela mídia.

Ainda segundo Herschmann (2000) no Rio de Janeiro, o hiphop esteve inicialmente atrelado ao movimento negro e o Tiro Inicial (1993) foi um dos primeiros lançamentos de disco na mídia, contando com o apoio do Centro de Articulação das Populações Marginais. Hoje, o hiphop atrai uma parte significativa dos jovens brasileiros e é difundido na mídia. O hiphop, tanto nos EUA quanto no Brasil, conta com espaços nos quais constrói seu cotidiano, onde os integrantes fazem reuniões, participam de ações comunitárias, realizam shows e festas. Outro espaço de socialização dessa manifestação cultural juvenil no Brasil, também chamada de «cultura das ruas», e que merece destaque, são as praças. Os b-boys (dançarinos) norteamericanos realizam sua arte nos guetos de Nova York e em Los Angeles, já os brasileiros realizam nas periferias ou praças dos grandes centros urbanos. O grupo Dançarinos de Rua por falta de espaço para manifestarem sua arte escolheram o Campo de São Bento, ${ }^{2}$ em Icaraí.

Observamos de junho de 2004 a março de 2006, os gestos repetidos partilhados nos rituais deste grupo, as calças rasgadas, o uso de boné, dread-looks nos cabelos, os comportamentos estereotipados, gestos com as mãos e os dedos. Tudo isso para mostrar no corpo as formas que tomam força no coletivo e lembram fusão e pertence. $\mathrm{O}$ corpo torna-se vetor de comunicação e identificação dos grupos de jovens.

Através dos relatos dos jovens e da observação da trajetória de cada integrante do grupo juvenil de dança, foi possível estabelecer relações mais próximas com esses sujeitos, conhecer seus anseios e aptidões, e melhor compreender suas culturas.

2 Campo de São Bento, área livre, arborizada, com Centro Cultural, parque infantil e escolas. Local onde ocorrem eventos artísticos na cidade de Niterói. 
Ao observar o cotidiano dos sujeitos desta pesquisa, o grupo Dançarinos de Rua, em suas práticas culturais, encontramos esta diversidade de expressão e de identidades culturais.

O hiphop engloba linguagens, costumes juvenis atuais e concepções de mundo; é compartilhado com vários tipos de artes como: desenho, dança, música e poesia e que se converteu em veículo de expressão e atitude juvenil compartilhadas. Trata-se de um fenômeno amplo, complexo, de uma época específica e que mostra os acontecimentos do mundo contemporâneo. Um bem de consumo popular que constrói identidades juvenis e se expressa em espaços de sociabilidade e nos meios de comunicação. Além da agregação juvenil que promove, o hiphop tem um discurso, uma estética a um nível simbólico que atrai os jovens, transcende as esferas territoriais e constitui-se como importante elemento para compreensão das agregações juvenis na atualidade. Vemos a relevância desses elementos nas pesquisas como, por exemplo, em Herschmann (2000) que aponta as expressões culturais juvenis como «espelhos de seu tempo». É o que Marta, integrante do grupo Dançarinos de Rua explica: «O break tem aqueles movimentos que imitam uma determinada realidade e de certa forma, pode ser educativo, trabalha a disciplina, a concentração, a coordenação de movimentos e a relação social».

A extensão do hiphop como referência cultural e referência para a construção de identidades juvenis, transcende a visão unilateral de influência da indústria cultural. Não queremos, entretanto, desprezar a influência da mídia na popularização do hiphop. Procuramos neste trabalho retratar a experiência do grupo Dançarinos de Rua, em busca de subsídios que permitam rever a posição da mídia no que tange as apropriações desses jovens no campo cultural. Constatamos na trajetória desse grupo de jovens que as experiências iniciaram-se por identificações e imitação de propostas veiculadas pela mídia, seguidas de um processo de socialização e solidariedade, a partir dos rituais da dança, da convivência diária e da diversidade de momentos partilhados. Há uma diversidade cultural, com antagonismos e contradições inerentes às sociedades urbanas contemporâneas onde os estilos aparecem e se modificam de acordo com as necessidades, valores e desejos dos atores sociais.

Breno coordena o grupo e isso envolve a responsabilidade de escolher as músicas, em ensaiar o grupo e elaborar um ritual para cada música. Ele conta que é um processo que envolve organização. Escolhe-se com a coreografia um símbolo ou uma letra que vai ser escri- 
ta com seus corpos na hora da dança.

Os indivíduos vivem múltiplos papéis e, assim encontram-se em determinados grupos na sociedade, como a escola, a família e a vizinhança. Estes são domínios distintos, podendo até demonstrar incompatibilidade, contudo, não há nada de estranho nesse fato já que a sociedade na qual vivemos apresenta planos e dimensões complexos e contrastantes. Há um movimento dialético no trânsito do indivíduo pelos diversos mundos dos quais faz parte, em cada mundo, ele partilha de códigos e interesses comuns e, ao mesmo tempo procura construir sua trajetória individual fazendo escolhas e avaliações da realidade.

O funk e o hiphop seduzem os jovens com a música e a dança com várias propostas tais como: lazer, prestígio, mobilidade social e inúmeras possibilidades de trabalho, por exemplo, iluminação em festas, montagem de som, programação visual, coreografia, dança, música, publicidade, divulgação, produção, televisão e rádio (Vianna, 1997). Propostas de inserção que motivam alguns componentes do grupo Dançarinos de Rua frente à dificuldade que revelaram ter para se interessarem por trabalhos convencionais. O problema que aparece é que nem sempre as expectativas condizem com a oportunidade de realização, os jovens buscam com essas atividades liberdade e autonomia (Madeira, 1986), procurando fugir das tarefas pesadas, monótonas e mal remuneradas oferecidas pelo escasso mercado de trabalho na atualidade (Vianna, 1997).

A diversidade de estímulos, de possibilidades, exige um esforço para a compreensão das visões de mundo desses atores sociais que não fazem reivindicações políticas com suas práticas, preocupam-se com a valorização da estética da dança e com as vestimentas. Para alguns o objetivo é só o lazer e, para outros a meta é a profissionalização.

Esses jovens apresentam uma forma lúdica de socialização e a base da construção das identidades, no grupo juvenil de dança, está na solidariedade e na estética, reconhecidas como meio de experimentar em comum e desenvolver relações no cotidiano, em outros espaços, diferentes dos institucionalizados. Um dos espaços que utilizam são as praças, onde acontecem alguns festivais.

A relação que estes jovens estabelecem com o tempo e suas projeções de futuro faz perceber que o presente é igualmente importante e valorizado, especialmente. O prazer de «estar junto» implica em ter momentos de reflexão, de teorias, de trocas culturais, de sensibilidade, de trabalho com o corpo e sensibilidade compartilhada. As festas, os festivais, os espetáculos funcionam como momentos de ligação, expe- 
riências com significado para todo o grupo, Breno contou como aconteceu um desses momentos de ligação: «Participamos de um festival no SESC, em Friburgo, em julho de 2003, o grupo estava com doze pessoas. Era legal participar de um grupo grande ao mesmo tempo difícil comandar tanta gente».

Uma componente do grupo, Marina conta que fez o curso de informática e não conseguiu o emprego desejado. O trabalho que surgiu foi num restaurante chinês e assim ela conseguiu seu primeiro emprego. A luta de Marina é pela sobrevivência, sua expectativa de vida é por independência, mas almeja executar um trabalho prazeroso. Para não ficar desempregada decide aceitar o emprego no restaurante chinês. Seu projeto com a informática foi abandonado. Quanto ao grupo de dança houve uma divergência em relação aos integrantes e ela por não desempenhar sua função como eles desejavam que o fizesse. Para ela, aquele era seu espaço de lazer e não de trabalho. Não queria ter tanta responsabilidade com horários e ensaios. Seu comportamento aparentemente desinteressado gerou conflito e ela saiu insatisfeita do grupo.

Marta, outra integrante do grupo, é uma jovem de 23 anos de idade que havia terminado o ensino médio e conseguido o primeiro emprego em telemarketing. Quando sua mãe faleceu ela tinha 2 anos de idade. Afirmou que a falta da mãe lhe causou instabilidade e isolamento. Revelou não se relacionar bem com a madrasta e que seu sonho é estudar artes cênicas. Seu relato aponta flexibilidade em seus projetos, inicialmente se interessou por teatro e somente depois pela dança: «No ensino médio estava completamente desligada, cheguei até a fazer parte de um grupo que pixava muros. Depois entrei para o grupo de dança Nikiti e tudo mudou» (Marta). Em relação ao trabalho ela demonstra um sentido de percepção e de adaptação à realidade. Suas opções para o trabalho estão relacionadas com a arte, com o movimento com o corpo, entretanto, o que aparece como trabalho é uma atividade em telemarketing. Ela está dois anos neste emprego. O trabalho para esta jovem pode estar associado ao prazer ou pode estar somente ligado ao aspecto econômico. A necessidade de ter independência, suprir necessidades de consumo e poder fazer escolhas. De qualquer forma, ela parece valorizar essas relações com o trabalho. Ela vê no trabalho atual uma forma de conquistar uma certa independência. 


\section{AS INTERAÇÕES E AS QUESTÕES INTERNAS DO GRUPO}

Os Dançarinos de Rua são jovens que vivem uma tensão provocada pela atual situação da sociedade vivida. Estudam, trabalham em atividades mal remuneradas e têm desejo de realização profissional, através de seus projetos em relação à dança. Seus projetos vão se modificando de acordo com as possibilidades e dificuldades encontradas na trajetória do grupo. Dentro do próprio grupo percebo também diferenciações em relação aos projetos de cada um. Há um movimento entre o individual e o coletivo, que gera tensões à medida que cada um dos elementos do grupo tem uma expectativa em relação à dança de rua.

A análise desses dois pontos, é considerada estratégica para a compreensão da construção de identidades urbanas juvenis. Através do movimento dialético entre esses pontos, percebemos nas experiências observadas, interseções nas trajetórias dos sujeitos e as redes sociais da qual fazem parte. Essa perspectiva aproxima-se das características relevantes na organização social, e do que Velho (2003:117) denomina de «negociação da realidade», ou seja, as trocas e as interações que constituem a vida social.

Ao analisar as interações deste grupo de jovens em seus processos culturais, também estão em jogo nos processos educativos que envolvem cada sujeito, suas necessidades, seus projetos e que os momentos vividos em grupo dão vigor à existência de cada um. Os projetos se interpenetram e os relacionamentos que os compõem dão origem à inúmeras redes de comunicação. Desse modo a subjetividade articula-se com o coletivo em ação contínua.

Essas redes de comunicação formadas por «microgrupos sociais e os âmbitos-sóciohistóricos se articulam para constituir planos contextuais da realidade do sujeito» (Carrano, 2003:35) e a subjetividade do sujeito constitui sentidos a partir da apropriação que ele faz do espaço/tempo disponível. Chrisna aponta as interações e o conflito que surgem em dado momento na trajetória do grupo: «Em outubro de 2004, Breno estava afastado, trabalhando em escritório o dia todo. Fiquei como coordenadora do grupo e Marta como diretora de ensaios, a Cia quase acabou».

Toda a movimentação desses jovens leva-nos à seguinte indagação: como os indivíduos desenvolvem identidades no contexto social globalizado tão farto de possibilidades quanto difícil na possibilidade da realização de projetos? Neste grupo os projetos vão se modificando 
de acordo com as possibilidades e dificuldades encontradas na sua trajetória. Nas sociedades moderno-contemporâneas percebe-se uma tendência de constituição de identidades a partir da dinâmica de papéis sociais que associam-se às experiências em contextos diversificados e papéis diferenciados. Quanto ao conceito de projetos, Velho (1999) aponta para o vasto campo de possibilidades que aparecem nas sociedades complexas, onde os indivíduos se fazem e se refazem através de suas trajetórias existenciais e esse processo viabiliza-se pela linguagem, que produz significados, relacionados às afinidades e principalmente às diferenças, porque como aponta Velho (2003), a comunicação entre as pessoas vive, sobretudo das diferenças. Acordos nos grupos são em dados momentos, inviáveis, mas, a desarmonia deixa explícito o particular, que origina novas possibilidades para cada um, no processo de construção de identidades.

Observamos transformações nos modelos tradicionais de inserção social e de construção de identidades, transformações que são traduzidas por experiências sociais significativas e que expressam uma parcela da população juvenil atual. Assim, a identidade é construída com plasticidade e como toda experiência humana é um processo dinâmico.

As pessoas mudam e os projetos também, o fato é que a transformação se dá com o tempo e conforme o contexto social. Vemos que o projeto existe no mundo da intersubjetividade, ele é instrumento expresso em conceitos, palavras, categorias que pressupõem a existência do outro. Ele é o instrumento de «negociação da realidade» (Velho, 2003) com os outros atores e existe como meio de comunicação, como forma de articular interesses, objetivos e desejos para o mundo. A sociedade organiza-se entre indivíduos e em suas redes de relações, onde acontecem conflitos, alianças, mas fundamentalmente, as trocas que constituem a própria vida social, através de experiências, de produção e do reconhecimento de interesses e valores.

Os Dançarinos de Rua utilizam o espaço/tempo de lazer como laboratório de seus projetos pessoais e os projetos do grupo, sendo que nessas vivências, eles estão sempre em transformação. Os ensaios, as apresentações do grupo e as experiências lúdicas que desenvolvem, salientam seus estilos de vida e a forma de participação social desses jovens. O grupo sofreu várias transformações e ficaram Breno e Chrisna que decidiram formar um duo e a partir de então, traçaram novas metas, tais como ensaiar uma coreografia nova e buscar novas competições. O nome também mudou e o grupo passou a se chamar Companhia Dançarinos de Rua. 
As pessoas mudam suas trajetórias de acordo com a resposta encontrada na realização, ou não, de cada meta estabelecida. As transformações individuais acontecem no contexto social e atualmente, o movimento desencadeado pela globalização e fragmentação na sociedade introduz novas dimensões às concepções de identidade social. Fatos que desencadeiam respostas nos diversos grupos sociais em todos os lugares. Os Dançarinos de Rua, em seu momento «duo» seguem nova etapa e novo projeto. Em maio de 2006, participaram de um campeonato no Colégio Plínio Leite e ganharam um troféu com a colocação em segundo lugar. Para Breno, a próxima meta é aumentar o grupo e continuar com novas apresentações.

\section{CONSIDERAÇÕES FINAIS}

A proposta deste trabalho foi investigar os processos de socialização vivenciados pelo grupo Dançarinos de Rua, procurando analisar suas experiências culturais e o sentido dessas práticas em suas vidas, ou seja, como estas práticas contribuem para a constituição de cada um como sujeito. Com essas questões procuramos entender como elaboram estilos e a representação deste espaço/tempo dedicado à dança, em suas vidas. Cada um tem outras atividades fora do grupo de dança, com destaque para o trabalho que buscam para ampliar o orçamento doméstico.

Os estilos de dança que praticam possibilitam a esses jovens, construções de valores para se fazerem sujeitos de suas próprias vidas. Eles desenvolvem esta sociabilidade em espaços inventados por eles mesmos e em eventos culturais que promovem.

Longe dos outros grupos, dos quais fazem parte, eles e elas formaram um outro grupo unidos pelo mesmo interesse com relação a dança. Neste grupo partilham práticas, representações, símbolos e rituais que geram sua participação no meio em que vivem, atraindo olhares dos que os cercam e conferindo-lhes visibilidade social e cultural.

O consumo e a produção cultural observada na atualidade, no contexto juvenil, vem mostrando novas formas de produção e formação desses jovens como atores sociais. Ou seja, apontam para novas formas de socialização e estas foram o principal foco de investigação deste trabalho.

Estes agrupamentos de jovens em torno da dança de rua e do rap, como expressão, denunciam situações da vida cotidiana nos meios urbanos como a exclusão social, a violência policial e as discrimi- 
nações sofridas pela população de bairros da periferia.

Outro fato significativo observado diz respeito à sociabilidade do grupo que permitiu, ainda que provisoriamente, a construção de um projeto coletivo em torno da dança. A diferença da tônica de uns no trabalho e de outros no lazer não permitiu que houvesse liga para que o grupo prosperasse. É possível dizer que apesar de todos estarem em condições de classe semelhantes, nem todos pensaram na dança como profissão.

A experiência de produção associada, vivenciada no grupo de dança, possibilita esses jovens reinventar construções, visando novas estratégias de sobrevivência, permitindo a superação da alienação dos trabalhos oferecidos no mercado. O associativismo é a questão de fundo dos projetos dos Dançarinos de Rua. Tal processo permite que as pessoas e os grupos se reúnam em determinadas atividades, para dar conta de transformar o lazer numa forma de trabalho remunerado, tendo em vista, a crise do trabalho.

Os jovens vivem, no momento, o esgotamento da promessa integradora na sociedade. Vivem a dificuldade de conseguir um lugar no mundo assalariado, descobrem assim, outras formas de trabalho onde a solidariedade está presente, fortalecendo a possibilidade de realização de seus projetos.

NITERÓI, R. J. (BRASIL), MAIO 2007

RECIBIDO: MAYO 2007

ACEPTADO: JULIO 2007

\section{REFERÊNCIAS BIBLIOGRÁFICAS}

Carrano, Paulo César Rodrigues (2002): Os jovens e a cidade. Rio de Janeiro: Relume Dumará, Faperj.

Dayrell, JuArez (2005): A música entra em cena. Belo Horizonte: Editora Humanitas.

IslAS, JosÉ ANTONIO PÉREZ (organizador): Jóvenes: una evaluación del conocimiento. Tomo I y II. México: Instituto Mexicano de la Juventud.

PAIS, José MACHADO (2004): Ganchos, tachos e biscates. Porto: Âmbar.

— y LeILA MARIA DA Silva Blass (2004): Tribos urbanas: produção artística e identidades. São Paulo: Anablume.

Velho, Gilberto (2003): Projeto e metamorfose. Rio de Janeiro: Jorge Zahar Editor. 